\title{
Modeling of Economic Processes, Instability and Chaos
}

\section{Evgenii Perevoznikov, Elena Lomteva}

\author{
A. F. Mozhaisky Military Space Academy, St. Petersburg, Russia \\ Email: eperevoznikov@yandex.ru
}

How to cite this paper: Perevoznikov, E. and Lomteva, E. (2019) Modeling of Economic Processes, Instability and Chaos. Journal of Applied Mathematics and Physics, 7, 356-363.

https://doi.org/10.4236/jamp.2019.72027

Received: January 16, 2019

Accepted: February 19, 2019

Published: February 22, 2019

Copyright ( 2019 by author(s) and Scientific Research Publishing Inc. This work is licensed under the Creative Commons Attribution International License (CC BY 4.0).

http://creativecommons.org/licenses/by/4.0/

\section{cc) (i) Open Access}

\begin{abstract}
We consider a mathematical model describing the dynamics of the three components of the economic activity of enterprises-production, management and resource consumption. For the analysis of the dynamics, the methods and criteria formulated by the authors earlier were used; new results of a practical nature were obtained; in particular, the calculation of the spectrum of small perturbations of the system depending on the input resource and system parameters is given. It is shown that the calculated values of the criteria of instability and chaos are fully consistent with the calculation of the spectrum, indicated the stability intervals of the system, as well as areas of instability and chaos.
\end{abstract}

\section{Keywords}

Mathematical Modeling of Economic Processes, Methods for Analyzing Dynamics, Instability, Chaos

\section{Introduction}

Methods of mathematical modeling are widely used to describe the economic processes [1]-[6].

Modeling of economic processes considers: 1) method of studying phenomena and processes in the economic system or its elements by building and studying their models; 2 ) transfer of the results obtained during the study of models to the original; 3) using models to determine or refine the characteristics; 4) building newly constructed objects in the economic system.

Forms of modeling are different and depend on models and scope. The idea of modeling is based on any method of scientific research of economic processes. There are many models that display various aspects of economic 
processes.

Modeling serves as a mean of studying the economy and the phenomena occurring in it, substantiating decisions made, forecasting, planning, managing economic processes and objects. A model of an economic object is usually supported by real statistical data, and the results of calculations carried out within the framework of the constructed model make it possible to build forecasts and carry out objective evaluations.

For successful modeling, justified simplifications in the model compared to the original are important; an analysis of fairly simple and representative dynamic models is necessary [1]-[6].

This article is a continuation of the work of the authors on the study of the dynamics of economic processes on the example of the "production-management-resource" model [7].

The considered model $P M R$ (production, management, resource) refers to the dynamic models of enterprises. Along with sufficient simplicity, it takes into account the main factors of production: the dynamics of production, management and the balance of external and system-produced resources. The model consists of three balanced, non-linear, differential equations corresponding to the three components of the required economic object subsystems-production, management and resource.

To analyze the dynamics of the system, assessing stability and possible instabilities, the methods and criteria given by the authors in [8] [9] [10] are used.

\section{Initial Relations}

Equations of the $P M R$ model in a dimensionless form

$$
\begin{aligned}
& \partial_{t} x=x(a-y+b z) \\
& \partial_{t} y=y(x-c+d z) \\
& \partial_{t} z=z(-e-d y-b x)-h x-k y+g x y+r
\end{aligned}
$$

Here, $\frac{(x, y, z)}{x_{0}+y_{0}+z_{0}}$ the main dynamic values having the same resource dimension (for example, monetary) are related to the sum of the initial values and corresponding to the dynamics of funds in the three subsystems of the object under study; $x$-production, $y$-control, $z$-resource. $t=\tau / \tau_{0}$-dimensionless time, $\tau_{0}$ - a characteristic financial time scale (quarter, year).

In the first equation of the system (1) describing the dynamics of production, the components $a x, b x z$ correspond to the profits from the production and input resource; the term $x y$ is a decrease in management (for example, for training, professional development, etc.). In the second equation for controlling $y x, d y z$, the flow of funds from production and the input resource; $c y$-direct management costs.

The third equation is the balance of the internal and external $r$ resource $(r>$ 0 -credit, $r<0$-debt repayment). 
The terms $h x, k y$ are the direct loss of the salary resource in production and management; $e z-$-resource costs for repayment of interest in lending or receiving interest on deposits, $b x z-$ resource costs for raw materials for production, energy, etc. The terms $g_{x y}, d_{y z}$, respectively, are the resource profit due to production $b$ and decrease on innovations in management and production automation.

The main task in the study of the dynamics is to identify areas of stable functioning of system (1), as well as areas and conditions for the occurrence of instabilities. This problem is solved by studying the spectrum of small perturbations of stationary states. The stationary state of the system-St $(x s, y s, z s)$ are

$$
\begin{aligned}
& x(a-y+b z)=0 \\
& y(x-c+d z)=0 \\
& z(-e-d y-b x)-h x-k y+g x y+r=0
\end{aligned}
$$

zeros of the right-hand sides of system (1), i.e. solutions of Equation (2). In this case, there are five stationary solutions, respectively

$$
\mathrm{St}_{1}(0,0, r / e) ; \mathrm{St}_{2}\left(0, y_{s}, c / d\right) ; \mathrm{St}_{3}\left(x_{s}, 0, z_{s}\right) ; \mathrm{St}_{4,5}\left(x_{s}, y_{s}, z_{s}\right)
$$

By linearizing system (1), we obtain a system of equations for perturbations

$$
\partial_{t} \delta x_{\alpha}=e_{\alpha \beta} \delta x_{\beta}, \quad\left\{\delta x_{\alpha}\right\}=\{\delta x, \delta y, \delta z\}
$$

where the elements of the evolutionary matrix are equal

$$
\begin{aligned}
& \hat{E}=\left\{e_{\alpha \beta}\right\} ; e_{11}=a-y_{s}+b z_{s}=0, e_{12}=-x_{s}=d z_{s}-c, e_{13}=b x_{s}, \\
& e_{21}=y_{s}=a+b z_{s}, e_{22}=x_{s}-c+d z_{s}=0, e_{23}=d y_{s}, \\
& e_{31}=-b z_{s}-h+g y_{s}=-h+g a-b g(1-g), \\
& e_{32}=-d z_{s}-k+g x_{s}=g c-k-d z_{s}(1+g), \\
& e_{33}=-e-d y_{s}-b x_{s}=-e-d a-b c .
\end{aligned}
$$

The condition of the solvability of the system (4) is the spectral equation (SE) equal to

$$
\operatorname{det}\left(\lambda \delta_{\alpha \beta}-e_{\alpha \beta}\right)=\lambda^{3}+s \lambda^{2}+p \lambda+q=0
$$

where $\lambda$ is the spectral parameter. The roots of this equation determine the dynamics of the system. Namely: if all the roots of SE have negative real parts, the state under study is stable with respect to small perturbations; if there is at least one root with a positive real part, the state is unstable; if there are roots in the spectrum with positive and negative real parts (saddle focus) and some of them are complex, then this is a special kind of instability-chaos (irregular chaotic oscillations).

$$
\operatorname{div} \vec{G}\left(\partial_{t} x, \partial_{t} y, \partial_{t} z\right)=-0.7+0.7 x-0.8 y+0.9 z
$$

Expression (6) - the divergence of the vector of the right-hand sides of equations (1) indicates the areas of growth and reduction of the phase volume and is one of the conditions for stability-instability. Depending on the sign $\operatorname{div} \vec{G}$, the dynamics is called active ( $\operatorname{div} \vec{G}>0)$, neutral $(\operatorname{div} \vec{G}=0)$, dissipative $(\operatorname{div} \vec{G}<0)$. 
From (6) it follows that, depending on the magnitude of the resource and the steady state, the system may have different types of dynamics.

\section{Spectral and Criterial Analysis of the Dynamics}

In view of the complexity of the system (1), only a numerical analysis of the spectrum is possible, for which it is necessary to specify the numerical values of the dimensionless coefficients, as well as select several (one, two) control parameters, varying the values of which monitor the changes in the spectrum and thus the system dynamics. As the control parameter, we select the parameter of the external resource $-r$, the parameters of innovation in management and production $-d, g$. The numerical values of the remaining parameters in the system (1) are selected in accordance with the real values on modern production and taking into account the preliminary account. So, in view of the above, the values of the parameters are chosen equal

$$
\left\{\begin{array}{l}
a=0.3, b=0.3, c=0.8, d=(-0.2 ; 0.4) \\
e=(-0.2 ; 0.2), h=0.2, k=0.4, g=(0.2 ; 0.4 ; 0.8), r \in(-0.4 ; 0.4)
\end{array}\right\}
$$

The spectral coefficients in (5) taking into account (7) take the form

$$
\begin{aligned}
& s=-\left(e_{11}+e_{22}+e_{33}\right), \quad p=-e_{12} e_{21}-e_{13} e_{31}-e_{23} e_{32}+e_{11} e_{22}+e_{11} e_{33}+e_{23} e_{32}, \\
& q=-e_{11}\left(e_{22} e_{33}-e_{23} e_{32}\right)+e_{33} e_{12} e_{21}+e_{22} e_{13} e_{31}-e_{12} e_{31} e_{23}-e_{13} e_{21} e_{32} .
\end{aligned}
$$

For the analysis of SEs, we use both the direct calculation of the roots of the spectral equation and the spectral criteria of instability and chaos given by the authors in [8] [9] [10]. According to these criteria, the relations defining the boundaries of the regions of instability and chaos are of the form

$$
q<0, \quad K 1=q-s p \geq 0 ; \quad \text { б) } \quad p>0 ; \quad \text { в) } \quad K 2=q \cdot K 1>0
$$

The first inequalities in (9) are instability conditions, the second is a sufficient condition for oscillations, the third is the saddle-like character of the spectrum, the realization of all three conditions reflects the presence of chaotic oscillations (chaos) in the system.

Of greatest practical interest are stationary states with nonzero values of quantities, i.e. $\mathrm{St}_{4}, \mathrm{St}_{5}$, for which, respectively, taking into account (2), (7), we obtain

$$
\begin{aligned}
& x_{4,5 s}=c-d z_{4,5} ; \quad y_{4,5 s}=b\left(1+z_{4,5}\right) ; \\
& z_{4.5 s}=\frac{-B \pm \sqrt{B^{2}-4 A D}}{2 A}, \quad A=-b d g, \quad D=a c g-h c-k a+r \\
& B=-d a(1+g)-b c(1-g)+h d-e .
\end{aligned}
$$

The values of the roots of the SE (5) and the criteria $q, K 1$, and $K 2$ for these states, depending on the parameter $r$, are given in Tables 1-4, respectively.

In Tables 1-2, it is taken into account that at $r>0.18$, the states 4.5 cease to be stationary. From Tables 1-2 it also follows that in the whole area of resource change, both with a shortage of credit and with its excess, the system is unstable, there are random fluctuations in it. Moreover, in the $\mathrm{St}_{4}$ state, they weakly decay, in the $\mathrm{St}_{5}$ state, damped oscillations are transformed into growing ones. In both 
Table 1. Estimated values of roots and criteria for the state $\mathrm{St}_{4}(e=d=-0.2, g=0.4)$.

\begin{tabular}{cccccccc}
\hline$r$ & -0.3 & -0.2 & -0.1 & 0.0 & 0.1 & 0.15 & 0.18 \\
$\Lambda_{1}$ & 0.178 & 0.169 & 0.157 & 0.140 & 0.110 & 0.082 & 0.044 \\
$\operatorname{Re} \Lambda_{2,3}$ & -0.079 & -0.074 & -0.068 & -0.060 & -0.045 & -0.031 & -0.012 \\
$\mathrm{iIm} \Lambda_{2,3}$ & $\pm 1.93 \mathrm{i}$ & $\pm 1.79 \mathrm{i}$ & $\pm 1.68 \mathrm{i}$ & $\pm 1.44 \mathrm{i}$ & $\pm 1.20 \mathrm{i}$ & $\pm 1.01 \mathrm{i}$ & $\pm 0.819 \mathrm{i}$ \\
$q$ & -0.66 & -0.54 & -0.42 & -0.29 & -0.16 & -0.084 & -0.089 \\
$K 1$ & -0.58 & -0.42 & -0.37 & -0.25 & -0.13 & -0.0064 & -0.016 \\
$K 2$ & $>0$ & $>0$ & $>0$ & $>0$ & $>0$ & $>0$ & $>0$ \\
\hline
\end{tabular}

Table 2. Calculated values of the roots and criteria for the state $\mathrm{St}_{5}(e=d=-0.2, g=0.4)$.

\begin{tabular}{cccccccc}
\hline$r$ & -0.3 & -0.2 & -0.1 & 0.0 & 0.1 & 0.15 & 0.18 \\
$\Lambda_{1}$ & 0.567 & 0.560 & 0.538 & 0.452 & 0.310 & -0.061 & -0.049 \\
$\operatorname{Re} \Lambda_{2,3}$ & -0.277 & -0.270 & -0.250 & -0.221 & -0.145 & +0.041 & +0.035 \\
$\mathrm{i} I m \Lambda_{2,3}$ & $\pm 0.725 \mathrm{i}$ & $\pm 0.620 \mathrm{i}$ & $\pm 0.501 \mathrm{i}$ & $\pm 0.378 \mathrm{i}$ & $\pm 0.233 \mathrm{i}$ & $\pm 0.275 \mathrm{i}$ & $\pm 0.483 \mathrm{i}$ \\
$q$ & -0.34 & -0.25 & -0.17 & -0.094 & -0.023 & 0.0047 & 0.011 \\
$K 1$ & -0.34 & -0.253 & -0.17 & -0.095 & -0.0235 & 0.0061 & 0.076 \\
$K 2$ & $>0$ & $>0$ & $>0$ & $>0$ & $>0$ & $>0$ & $>0$ \\
\hline
\end{tabular}

Table 3. Calculated values of the roots and criteria for the state $\mathrm{St}_{4}(e=0.2, d=-0.2, g=$ $0.4)$.

\begin{tabular}{cccccccc}
\hline$r$ & -0.3 & -0.2 & -0.1 & 0.0 & 0.1 & 0.2 & 0.3 \\
$\Lambda_{1}$ & -0.057 & -0.058 & -0.058 & -0.059 & -0.060 & -0.061 & -0.062 \\
$\operatorname{Re} \Lambda_{2,3}$ & -0.161 & -0.161 & -0.161 & -0.160 & -0.160 & -0.160 & -0.159 \\
$\operatorname{iIm} \Lambda_{2,3}$ & $\pm 5.70 \mathrm{i}$ & $\pm 5.64 \mathrm{i}$ & $\pm 5.56 \mathrm{i}$ & $\pm 5.52 \mathrm{i}$ & $\pm 5.46 \mathrm{i}$ & $\pm 5.39 \mathrm{i}$ & $\pm 5.33 \mathrm{i}$ \\
$q$ & 1.86 & 1.84 & 1.82 & 1.80 & 1.78 & 1.70 & 1.74 \\
$K 1$ & -10.5 & -10.3 & -10.0 & -9.8 & -9.5 & -9.3 & -9.0 \\
$K 2$ & $<0$ & $<0$ & $<0$ & $<0$ & $<0$ & $<0$ & $<0$ \\
\hline
\end{tabular}

Table 4. Calculated values of the roots and criteria for the state $\mathrm{St}_{5}(e=0.2, d=-0.2, g=$ $0.4)$.

\begin{tabular}{cccccccc}
\hline$r$ & -0.3 & -0.2 & -0.1 & 0.0 & 0.1 & 0.2 & 0.3 \\
$\Lambda_{1}$ & 0.107 & -0.306 & -0.360 & -0.378 & -0.381 & -0.376 & -0.366 \\
$\operatorname{Re} \Lambda_{2,3}$ & -0.243 & -0.037 & -0.010 & -0.0011 & 0.00066 & +0.0018 & +0.0070 \\
$\operatorname{iIm} \Lambda_{2,3}$ & $\pm 0.016 \mathrm{i}$ & $\pm 0.21 \mathrm{i}$ & $\pm 0.32 \mathrm{i}$ & $\pm 0.41 \mathrm{i}$ & $\pm 0.47 \mathrm{i}$ & $\pm 0.54 \mathrm{i}$ & $\pm 0.60 \mathrm{i}$ \\
$q$ & -0.009 & 0.015 & 0.037 & 0.061 & 0.085 & 0.11 & 0.14 \\
$K 1$ & -0021 & -0.012 & -0.0049 & -0.0007 & 0.00005 & -0.0016 & -0.017 \\
$K 2$ & $>0$ & $<0$ & $<0$ & $<0$ & $>0$ & $<0$ & $<0$
\end{tabular}


cases, the signs of the criteria correspond to the signs of the roots and the presence of chaos.

Tables 3-4 reflect the dynamics of the system with increased resource due to management.

It follows from them that the state $\mathrm{St}_{4}$ is stable in the entire range of the parameter $r$, i.e. management maintains state stability regardless of resource change. In contrast, the $\mathrm{St}_{5}$ state is more dynamic than the $\mathrm{St}_{4}$ state; in it areas of stability $r \in(-0.2 ; 0.0) \cup(0.2 ; 0.3)$ alternate with areas of chaos $r<-0.2: r \sim 0.1$.

The tables imply a significant influence on the system dynamics of the parameter $d$.

Also in these cases, the signs of the criteria correspond to the signs of the roots and the presence of chaos.

Figures 1-4 show the graphs of the dependence of the conditions of instability and chaos on the parameters $r, g, d$ demonstrating the influence of these parameters on the dynamics of the system.

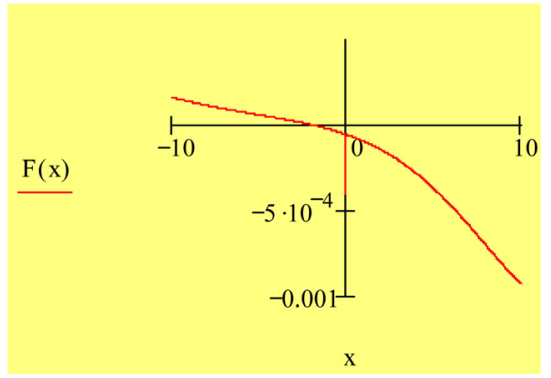

Figure 1. $r=-0.2, g=0.2$.

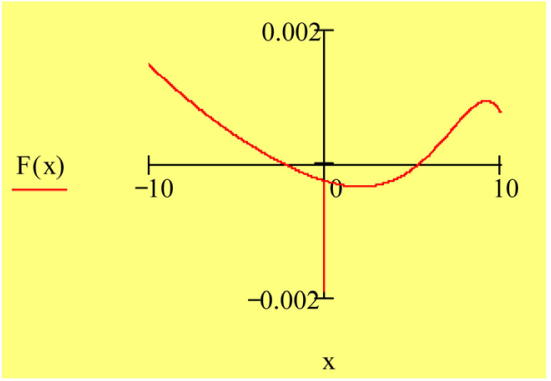

Figure 2. $r=-0.2, g=0.8$.

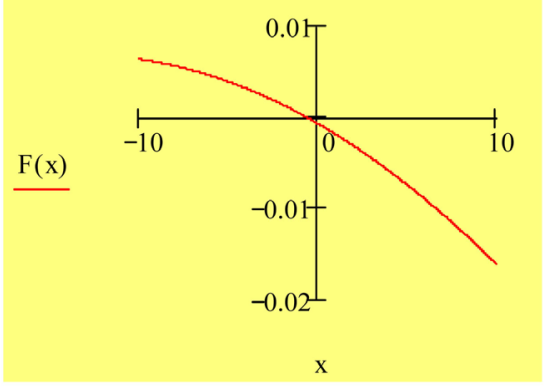

Figure 3. $r=0.2, g=0.2$. 


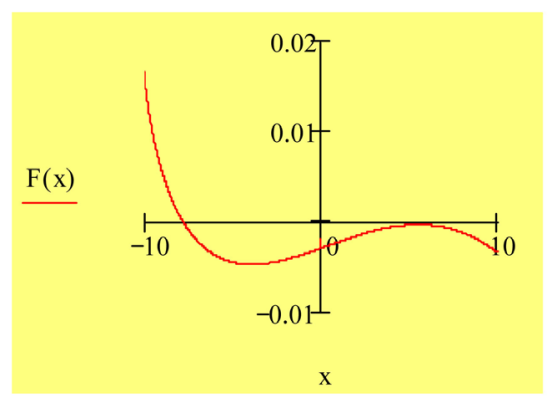

Figure 4. $\mathrm{r}=0.2, \mathrm{~g}=0.8$.

In Figures 1-4 $(\mathrm{F}=\mathrm{K} 2$ is the condition of chaos, $x=10 d)$. The dependence of the condition of the existence of chaos on the parameter $d$ is shown. From Figures 1-4 it follows that

1) The system is very sensitive to changes in the parameter $d$;

2) With a small innovation parameter (small value of $g$ parameter), the growth of $d$ parameter stabilizes the system (see Figures 1-3);

3) With an increase in innovation (a larger value of the parameter $g$ ), the parameter $d$ destabilizes the system, windows of chaos appear (see Figure 2-4);

4) Significant negative values of the parameter $d$, i.e. a decrease in the contribution to control and a corresponding increase in accumulations leads to the initiation of chaotic oscillations-the "fever" system.

\section{Conclusions}

In general, analyzing the results of calculations, the following can be noted:

1) The proposed model provides ample opportunities to study the impact on the economic activity of enterprises of various factors of the production, management and resource sphere.

2) This model describes a very dynamic system, in which, along with the areas of stability, there are areas of instability and chaos, significantly dependent on the parameters of the system.

3) From the tables and graphs it can be seen that the increase in the financing of management stabilizes the processes in the system and that the system loses stability both with a shortage and with an excess of resources.

4) The criteria of instability and chaos proposed by the authors are fully consistent with the calculation of the spectrum, i.e. can be used to predict areas of stability as well as instability of dynamic systems.

\section{Conflicts of Interest}

The authors declare no conflicts of interest regarding the publication of this paper.

\section{References}

[1] Mazhukin, V.I. and Flinta, M. (2004) Moskovskij gumanitarnyj universitet. Matematicheskoe modelirovanie v ehkonomike, $232 \mathrm{~s}$. 
[2] Markin, M.P. (2007) Matematicheskie metody i modeli v ehkonomike. M. Vysshaya shkola, $422 \mathrm{~s}$.

[3] Hachatryan, N.K. (2008) Matematicheskoe modelirovanie ehkonomicheskih sistem. M., EHkzamen, $158 \mathrm{~s}$.

[4] Vihanskij, O.S. and Naumov, O.I. (2010) Menedzhment: chelovek, strategiya, organizaciya, process. M. Delo, $383 \mathrm{~s}$.

[5] Kabushkin, N.I. (2008) Osnovy menedzhmenta. M.: Novoe znanie, 336 s.

[6] Klejner, G.B. (2010) Razvitie teorii ehkonomicheskih sistem i ee primenenie v operativnom i strategicheskom upravlenii, WP /2010/CEHMI RAN, 209 s.

[7] Perevoznikov, E.N. and Skvorcov, G.E. (2018) Analiz dinamiki model'noy sistemy $<$ Proizvodstvo, Upravleniye, Resurs> "Vestnik Sankt-Peterburgskogo gosudarstvennogo universiteta tekhnologii i dizayna. ser. Yestestvennyye $i$ tekhnicheskiye nauki, 2, 41-48.

[8] Perevoznikov, E.N. (2006) Metody analiza ustojchivosti neravnovesnyh system. Izv. Vuzov, Fizika, 10, 34-39.

[9] Skvorcov, G.E. and Perevoznikov, E.N. (2016) Teoriya neustojchivosti i kriterii haosa. Mezhdunarodnyj nauchno-issledovatel'skij zhurnal, fiziko-matematicheskie nauki, ch.4.-C.98-101.

[10] Perevoznikov, E.N. and Skvortsov, H.E. (2018) Criteria for Instability and Chaos in Nonlinear System. Journal of Applied Mathematics and Physics, 6, 382-388.

https://doi.org/10.4236/jamp.2018.62036 